\title{
DEVELOPMENT OF BUILDING-FAÇADE MAINTENANCE ROBOT WITH DOCKING STATION BASED ON VERTICAL CLIMBING MECHANISM
}

\author{
Sung Min Moon, Dae Hie Hong*, Sung Won Kim, and So Ra Park \\ Department of Mechanical Engineering, Korea University, Seoul, Korea \\ *Corresponding author (dhhong@korea.ac.kr)
}

\begin{abstract}
There are a large number of high-rise buildings equipped with facades (curtain-walls) in modern cities. These facades must be periodically maintained with manual procedures that are costly and risky. For this reason, the interest in developing and employing service robots for the building maintenance has been increased. Automation and robotics technologies allow safe and environmentally friendly facade cleaning, monitoring, and painting, which also reduce the cost of these tasks. These systems resolve the current safety problems associated with difficult and dangerous access, contributing to a zero injury and fatality working performance. This paper deals with developing a Built-in Facade Maintenance Robot System (BMR) with Docking Station based on vertical climbing mechanism and daughter robot for actual maintenance works.
\end{abstract}

Keywords: Built-in Guide Robot System, Façades, Curtain-Wall, Docking Station, Climbing Mechanism, Maintenance

\section{INTRODUCTION}

The architecture trend of recently high-rise building reflects complicated surface and irregular shape. The highrise buildings require the development and realization of maintenance system in order to reach and clean them properly. Most of the maintenance robot system developed in the past consists of a semi-automatic system. In addition, in the case of an existing maintenance robotic system, most of the robotic system is performed moving by the cabledriven type system.[1-3] For the development of differentiated systems by comparing with the existing system is required full-automation and creativity mechanism for maintenance robot system. The interest in the research field of fully-automation facade maintenance robot systems was generated by the fact that facade surfaces are often difficult to access by people. Thus a large number of recurring operations on vertical/horizontal surfaces(facades) will frequently require for maintenance automation work. Developing a robotic platform for precise movement on a vertical / horizontal surface based on built-in guide rail and handling complex tools for specific tasks is a logical first step in the introduction of automation to in any new field of application.

\section{MOCK-UP BUILDING WITH GUIDE RAIL}

Important topic of maintenance robot system include safety contact between robot and façades, being able to overcome various obstacles and being able to move efficiently along the façades. We suggest new concept building that installed built-in guide rail. The built-in system that consist of vertical rail and horizontal rail is best suited for providing safety contact to façades on building. That is, through using rails, the system could not contact window directly, and would impose the load on the rail rather than window.

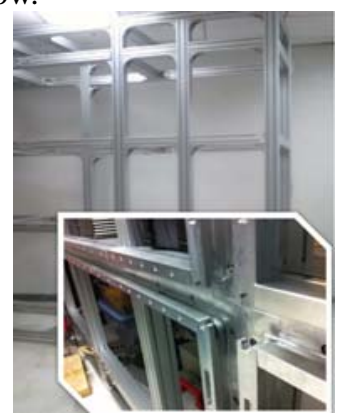

Fig 1. Mock-up Building with Built-in Guide Rail

\section{BUILT-IN GUIDE MAINTENANCE ROBOT}

The Built-in guide Robot System(BMR) consist of 
vertical climbing system and horizontal moving system. For vertical moving on building-facade, commercial carrier systems (gondola) have been usually used in many highrise buildings, which carry maintenance workers and tools on the building facade. However, the proposed system consists of built-in guide rail mounted on the facade of high-rise buildings, inch-worm system based on hook mechanism for vertical climbing that has been frequently used in construction fields due to its safety nature despite complicated climbing patterns. The system also contains the docking connector for getting a supply of materials from building and the electric valve system to control it.

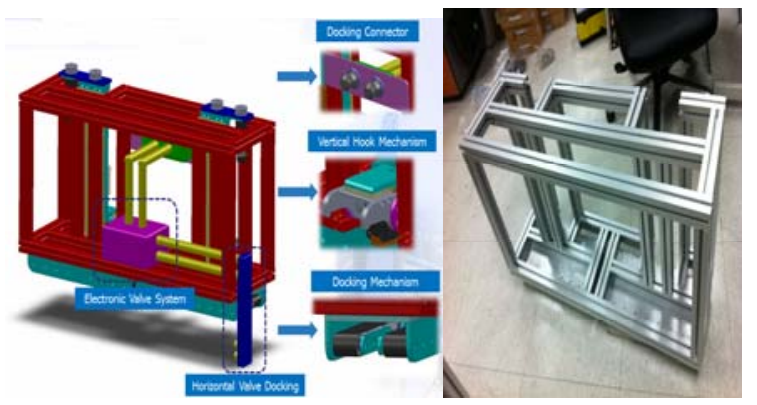

Fig 2. Vertical Climbing System

The lifting system of the BMR includes coupling device for holding and vertically carrying the daughter robot. The daughter robot horizontally moves along the built-in guide rail and perform the maintenance works using tool mechanism. The horizontal moving mechanism is composed of intersection wheels that are designed to be connected to the built-in guide rail for removability and anti-shock damping mechanism.

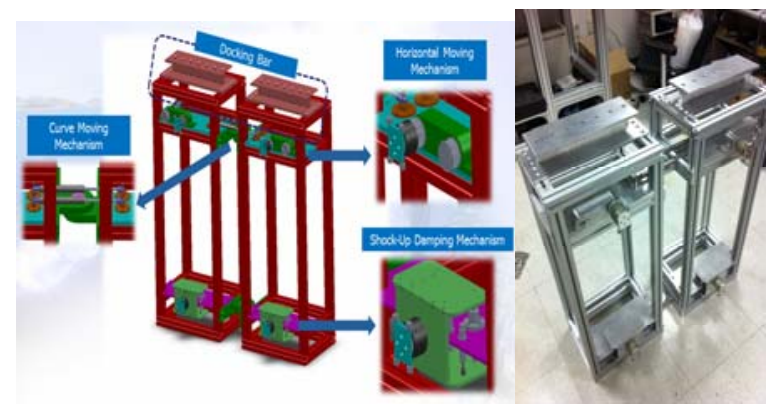

Fig 3. Horizontal Moving System

Whole system is integrated vertical climbing mechanism and horizontal moving mechanism by built-in guide rail installed on mock-up building..

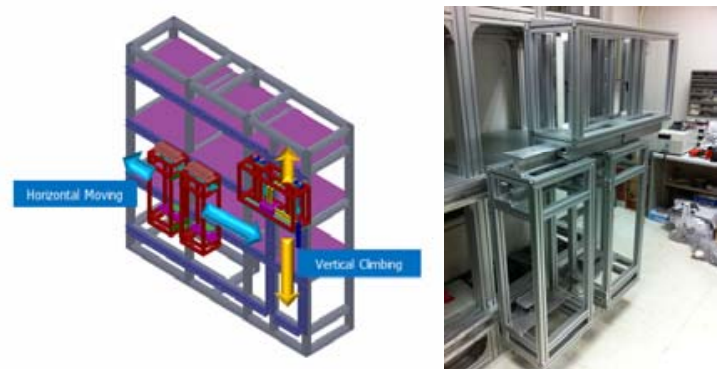

Fig 4. Built-in Guide Maintenance Robot System

\section{CONCLUSION}

This paper describes a new kind of built-in guide maintenance robot system actuated by inch-worm climbing mechanism and horizontal wheel moving mechanism. After the development of the proto-type maintenance tool modules, the complete cleaning system was integrated. A wide range of applications in building maintenance is possible for the BMR system because of its adapted removability, improved hook mechanism and increased load capacity.

\section{ACKNOWLEDGE}

The work presented in this paper was funded by BMRC(Building-Façade Maintenance Robot Research Center), supported by Korea Institute of Construction and Transportation Technology Evaluation and Planning (KICTEP) under the Ministry of Land, Transport and Maritime Affairs(MLTM)

\section{REFERENCES}

[1] Elkmann N., Felsch T., Sack M., Böhme T., Saenz J., ”Sirius: Modular climbing robot for facade cleaning and other service jobs”, proceedings of 3rd international conference on field and service robots, 2001, pp. 403 - 407

[2] H. Zhang, J. Zhang, and G. Zong, "Requirements of glass cleaning and development of climbing robot systems," in Proc. 2004 IEEE Int. Conf. Intelligent Mechatronics Automation, 2004, pp. 101-106.

[3] Zhi-Yuan Q., Yan-Zheng Z., Zhuang F., Qi-Xin C., "Design and realization of a non-actuated glass-curtain wall-cleaning robot prototype with dual suction cups”, Int J Adv Manuf Technol, 2006, pp.147-155 